\title{
Erratum to: Structural and functional changes of cortical and subcortical structures following peripheral vestibular damage in humans
}

\author{
Maxime Maheu $^{1,2,3} \cdot$ Philippe Fournier ${ }^{1,2,3} \cdot$ Simon P. Landry ${ }^{1,2,3}$ • \\ Marie-Soleil Houde $^{1}$ - François Champoux ${ }^{1,2,3} \cdot$ Issam Saliba $^{4,5}$
}

Published online: 25 April 2016

(c) Springer-Verlag Berlin Heidelberg 2016

\section{Erratum to: Eur Arch Otorhinolaryngol 10.1007/ s00405-016-3986-5}

The original article was published with the incorrect author group. The correct author group is provided below:

Maxime Maheu · Philippe Fournier · Simon P. Landry · Marie-Soleil Houde · François Champoux · Issam Saliba
Also, the family names for three authors were incorrect in the original publication. The correct given and family names should read as Maxime Maheu, Philippe Fournier and François Champoux.

The original article has been updated with the correct author group accordingly.

The online version of the original article can be found under doi:10.1007/s00405-016-3986-5.

Issam Saliba

issam.saliba@umontreal.ca

1 Faculty of Medicine, School of Speech Language Pathology and Audiology, University of Montreal, Montreal, QC, Canada

2 Center for Interdisciplinary Research in Rehabilitation of Greater Montreal, Raymond-Dewar Institute, Montreal, QC, Canada

3 International Laboratory for Research on Brain, Music, and Sound (BRAMS), University of Montreal, Montreal, QC, Canada

4 Department of Surgery, Division of OtorhinolaryngologyHead and Neck Surgery, University of Montreal, Montreal, QC, Canada

5 Division of Otolaryngology Head and Neck Surgery, Montreal University Hospital Center (CHUM), Notre-Dame Hospital, 1560 Sherbrooke street East, Montreal, QC H2L 4M1, Canada 